\title{
Computer-aided analysis of saturation in synchronous machines
}

\author{
Sourish Sanyal ${ }^{*}$, Sohorab Hossain ${ }^{2}$, Sujit Dhar ${ }^{3}$, Amar N. Sanyal $^{4}$ \\ ${ }^{1}$ ECE Department, Techno India, Salt Lake, Kolkata, 700091, India \\ ${ }^{2}$ EE Department, MCKV Institute of Engineering, Howrah, 711204, India \\ ${ }^{3}$ EEE Department, NEOTIA Institute of Technology Management and Science, Kolkata, 743368, \\ India \\ ${ }^{4}$ EE Department, CIEM, Kolkata (formerly faculty member, Jadavpur University), 743368, India \\ Email: ansanyal@yahoo.co.in
}

\begin{abstract}
There are a number of secondary effects in a synchronous machine which are most often neglected to develop a simplified model. This procedure is simple and straight-forward, but it gives rise to much errors. To avoid the errors, the modelers have developed several techniques. Saturation is one of the secondary effects which become quite dominant at certain load conditions. In the earlier regimes, grapho-analytical techniques were developed to treat the effect of saturation. But such methods were tedious, complex and time-consuming. Now they should be replaced by computer methods. This paper gives a comprehensive discussion on the various methods developed to treat the effect of saturation. It also gives computer-aided methods to replace the older methods.
\end{abstract}

Keywords: Saturation, Grapho-analytical Technique, Exponential Method, Frolich's Equation, Method of Least Square.

\section{INTRODUCTION}

There are secondary effects in a synchronous machine which affect the performance variables- they affect the transient as well as steady state performance [1]. The secondary effects are:

i) saturation of the magnetic circuits,

ii) space and time harmonics and

iii) distributed eddy currents in solid metallic parts.

Many authors and modelers have made analysis in this area and bulk of papers has been advanced [2, 3, 4, 5, 6]. Out of these three, saturation also affects the performance of exciters and transformers [7]. Saturation cannot be avoided in machines/ transformers for economic reasons. So, its effect should be accounted for in circuit analysis and design of electrical machines $[8,9,10]$. So only the effect of saturation is being focused in this paper.

The methods improvised in the past were mostly graphoanalytical, as such tedious and time-consuming. They offered various degrees of accuracy. In this paper, the commonly used methods are being discussed and computer methods are being developed to replace the grapho-analytical.

\section{THE EXISTING METHODS}

There are several techniques to account for saturation in synchronous machine $[2,3,5]$ and exciters. These are as given below: a. Kingsley's method of saturated synchronous reactance.

b. The technique developed by Anderson and Fouad.

c. Frolich's method

d. Modified Frolich's method

e. Exponential method.

Kennelly was also associated with Frolich in his works on saturation. These methods are being discussed one after another along with techniques for computer-aided solutions $[11,12]$. For computer-based solutions higher mathematics [13] and numerical methods [14] are adopted.

\section{THE KINGSLEY'S METHOD}

The Kingsley's method is the simplest one and is commonly used. This is a grapho-analytical method, by which a saturation factor is found out from the OCC/SCC of the machine. The unsaturated synchronous reactance is found out from these curves and the saturated synchronous reactance [15] is found out from:

$X_{d s}=x_{a}+\left(X_{d u}-x_{a}\right) / k$

The saturated value of synchronous reactance is used instead of the unsaturated one for computations on stability etc. To find out the saturation factor, the steps are as given below:

a. Plotting the OCC and extend its linear part to get the airgap line. 
b. Find out the voltage behind the armature leakage reactance at full load:

c. $E_{r}=V+I_{a}\left(r_{a}+j x_{a}\right) \simeq V+I_{a}\left(j x_{a}\right)$

d. $x_{a}$ is obtained from manufacturer's data. The effect of $r_{a}$ is very small and negligible.

e. Finding out excitation required to produce $E_{r}$ on the airgap line (OA)

f. Finding out excitation required to produce $E_{r}$ on the OCC (OB)

g. Finding out the saturation factor $k=\mathrm{OB} / \mathrm{OA}$

h. Finding out unsaturated synchronous reactance $X_{d u}$ from the air-gap line and SCC.

i. Finding out the base values from the rating of the machine and the p.u. values of reactance.

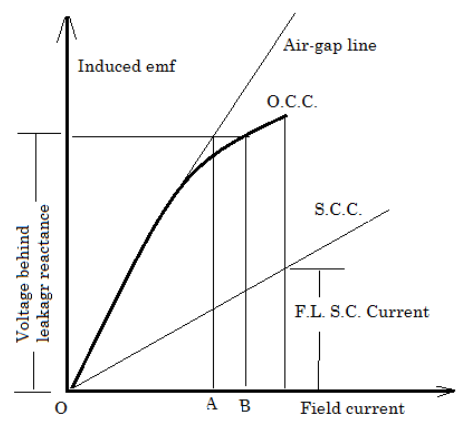

Figure 1. The OCC and SCC of a turbo-generator

\subsection{Case-study on Kingsley's method}

Saturated synchronous reactance is being found out by KINGSLEY'S method. The data is obtained from reference [16].

The machine in the case study is the $5^{\text {th }}$ unit of BANDEL TPS, manufactured by BHEL.

MW-rating $=210 ;$ Rated power factor $=0.85 \mathrm{lag}$

Rated L-L voltage $=15.75 \mathrm{kV}$

The corresponding MVA-rating $=247$.

The data for OCC is given below:

Table 1. Data for OCC of the synchronous generator

\begin{tabular}{|c|c|c|c|}
\hline $\begin{array}{c}\text { Field } \\
\text { current, A }\end{array}$ & $\begin{array}{c}\text { Induced } \\
\text { emf, V }\end{array}$ & $\begin{array}{c}\text { Field } \\
\text { current, A }\end{array}$ & $\begin{array}{c}\text { Induced } \\
\text { emf, V }\end{array}$ \\
\hline 100 & 1800 & 1300 & 19100 \\
\hline 200 & 3600 & 1400 & 19650 \\
\hline 300 & 5400 & 1500 & 20100 \\
\hline 400 & 7200 & 1600 & 20600 \\
\hline 500 & 9000 & 1700 & 21000 \\
\hline 600 & 10800 & 1800 & 21400 \\
\hline 700 & 12600 & 1900 & 21800 \\
\hline 800 & 14200 & 2000 & 22150 \\
\hline 900 & 15600 & 2100 & 22450 \\
\hline 1000 & 16700 & 2200 & 22700 \\
\hline 1100 & 17700 & 2300 & 22900 \\
\hline 1200 & 18500 & 2400 & 23100 \\
\hline
\end{tabular}

The OCC is linear up to an excitation of $700 \mathrm{~A}$ while it induces a line voltage of 12600 volts (L-L).

The slope of the air-gap line $=18 \mathrm{~V} / \mathrm{A}$
Field current to produce rated voltage on a-g line $=875 \mathrm{~A}$

Base current of the machine $=9056.5 \mathrm{~A}$

Field current required to produce f.1. short-circuit current $=$ $1850 \mathrm{~A}$

S.C. current at field current corresponding to rated a.g. voltage $=4283.5 \mathrm{~A}$

The value of $\mathrm{d}$-axis unsaturated synchronous reactance $=$ $2.1229 \Omega$

The base impedance $=1.0041 \Omega$

The value of $\mathrm{d}$-axis unsaturated synchronous reactance $=$ 2.1143 p.u.

The p.f. angle at rated loading $=31.791^{\circ}$

The voltage behind leakage reactance $=1.0878$ p.u.

The reqd. field current at $E_{r}$ is obtained by linear approximation.

Field current required to produce $E_{r}=1043.2 \mathrm{~A}$

Field current required to produce $E_{r}$ on a.g. line $=951.8$ A

$S_{G 1.2}=A_{G} e^{B_{G} 0.4} S_{G 1.2}=A_{G} e^{B_{G} 0.4}$

The saturation factor $=1.09607$

The saturated synchronous reactance $=1.9423$ p.u. (Compared to unsaturated $=2.1143$ p.u.)

The method of synchronous reactance is simple and straight-forward but it produces errors- its accuracy is limited. Moreover, the value of the saturated synchronous reactance depends on the load.

\section{THE METHOD SUGGESTED BY ANDERSON AND FOUAD}

Anderson and Fouad [3] in their famous treatise on power system have suggested a rather simple method to account for saturation of the generator. They have defined a p.u. saturation factor $S_{G}$. It is defined in terms of O.C. terminal voltage and field current. As an example, with reference to fig. $1, S_{G}$ at

$E_{r}=(\mathrm{OB}-\mathrm{OA}) / \mathrm{OA}$

With this definition, we specify $S_{G}$ for two values of terminal voltage 1.0 and 1.2 p.u. as $S_{G 1} \& S_{G 1.2}$ following eqn. 3. P.U. $S_{G}$ is given as: $S_{G}=A_{G} e^{B_{G} V_{\Delta}}$, where

$V_{\Delta}=V_{t}-V_{t h}=V_{t}-0.8$

From these equations, we get: $S_{G 1}=A_{G} e^{B_{G} 0.2}$;

$1.2 S_{G 1.2}=A_{G} e^{B_{G} 0.4}$

which yield the following expressions:

$A_{G}=S_{G 1}^{2} /\left(1.2 S_{G 1.2}\right) ; B_{G}=5 \ln \left(1.2 S_{G 1.2} / S_{G 1}\right)$

The saturation factor can be estimated from these expressions for any operating voltage. 
4.1.1 Case study on Anderson and Fouad' method

Slope of the air-gap line $=18 \mathrm{~V} / \mathrm{A} S_{G}$

There is no saturation up to field current, $\mathrm{I}_{\mathrm{f}}=700 \mathrm{~A}$

The Saturation starts at a field current, $I_{f}=800 \mathrm{~A}$

Threshold voltage $=0.8$ p.u.

Field current required for developing rated voltage on a.g. line $=875 \mathrm{~A}$

Field current required to produce rated voltage at no load $=913.64 \mathrm{~A}$

Field current required to produce $20 \%$ overvoltage on airgap line $=1050 \mathrm{~A}$

Field current required to produce $20 \%$ overvoltage at no load $=1266.7 \mathrm{~A}$

Normalized saturation function: $\mathrm{SG}_{1}=4.4156 \mathrm{E}-02: \mathrm{SG}_{2}=$ 0.20635

Saturation as an exponential function:

$\mathrm{SG}=7.8739 \mathrm{E}-03 \times \mathrm{e}^{8.6208 \times \mathrm{V}_{\Delta}} ;$ where $V_{\Delta}=\mathrm{V}-\mathrm{V}_{\mathrm{t}}$

\section{THE EXPONENTIAL METHOD}

There is another way to account for saturation. That is the exponential method. In this method, the describing eqn. is given as:

$$
E=a I_{f}^{b}
$$

The equation can be re-written as:

$\log E=\log a+b \cdot \log I_{f}$

In this form, it is the equation of a straight line and the method of linear regression can be applied to it $[13,14]$. The case-study is given below.

\subsection{Fitting exponential equation to $\mathrm{OCC}$}

Table 2. Actual and calculated values by the exponential method

\begin{tabular}{|c|c|c|c|}
\hline If, $\mathrm{A}$ & Eactual, $\mathrm{V}$ & Ecalcu., $_{\text {, }}$ & \% deviation \\
\hline 800 & 14200 & 14294 & 0.6637 \\
\hline 900 & 15600 & 15120 & -3.0749 \\
\hline 1000 & 16700 & 15900 & -4.7926 \\
\hline 1100 & 17700 & 16639 & -5.9934 \\
\hline 1200 & 18500 & 17344 & -6.2470 \\
\hline 1300 & 19100 & 18019 & -5.6581 \\
\hline 1400 & 19650 & 18668 & -4.9991 \\
\hline 1500 & 20100 & 19292 & -4.0187 \\
\hline 1600 & 20600 & 19895 & -3.4205 \\
\hline 1700 & 21000 & 20479 & -2.4804 \\
\hline 1800 & 21400 & 21045 & -1.6582 \\
\hline 1900 & 21800 & 21595 & -0.9405 \\
\hline 2000 & 22150 & 22130 & -0.0910 \\
\hline 2100 & 22450 & 22651 & 0.8949 \\
\hline 2200 & 22700 & 23159 & 2.0227 \\
\hline 2300 & 22900 & 23655 & 3.2989 \\
\hline 2400 & 23100 & 24141 & 4.5047 \\
\hline 2500 & 23250 & 24615 & 5.8721 \\
\hline 2600 & 23400 & 25080 & 7.1799 \\
\hline
\end{tabular}

The sum of squares of \% deviation (in the saturated zone for $\left.I_{\mathrm{f}}>=800 \mathrm{~A}\right)=324.6$

The least square line is being fitted to saturation curve:
The fitting eqn. for the saturation curve is given below:

$$
\mathrm{E}=589.37 \times \mathrm{I}_{\mathrm{f}}^{0.477}
$$

Checking the fitting:

The actual values are being compared with the calculated values using the exponential method and are given in table 2 .

\section{FROLICH'S EQUATION}

One of the methods is fitting Frolich's equation to the saturation curve data. Frolich has proposed the following equation for the saturation curve:

$$
E_{f}=\frac{\mathrm{a} I_{f}}{\mathrm{~b}+I_{f}}
$$

To fit this eqn. to saturation curve, by the method of linear regression, the following modification has to be made:

$\frac{1}{E_{f}}=\frac{1}{I_{f}} \frac{b}{a}+a$

This is the eqn. of a straight line. Hence the method linear regression can be used [13, 14].

\subsection{Fitting Frolich's equation to saturation curve by least square line}

The fitting eqn. for the saturation curve using the method of least squares is given below:

$E_{f}=\frac{35067 I_{f}}{1154+I_{f}}$

Checking the fitting:

The actual values obtained by Frolich's method are being compared to the calculated values and is given in table 3.

Table 3. Actual and calculated values by the Frolich's method

\begin{tabular}{|c|c|c|c|}
\hline $\begin{array}{c}\text { Field } \\
\text { current, } \mathrm{A}\end{array}$ & $\mathrm{E}_{\text {actual }}$ & $\mathrm{E}_{\text {calcu. }}$ & $\%$ deviation \\
\hline 800 & 14200 & 14356 & 1.1032 \\
\hline 900 & 15600 & 15365 & -1.5069 \\
\hline 1000 & 16700 & 16280 & -2.5175 \\
\hline 1100 & 17700 & 17113 & -3.3160 \\
\hline 1200 & 18500 & 17876 & -3.3743 \\
\hline 1300 & 19100 & 18576 & -2.7421 \\
\hline 1400 & 19650 & 19222 & -2.1785 \\
\hline 1500 & 20100 & 19819 & -1.3983 \\
\hline 1600 & 20600 & 20373 & -1.1039 \\
\hline 1700 & 21000 & 20887 & -0.5359 \\
\hline 1800 & 21400 & 21367 & -0.1521 \\
\hline 1900 & 21800 & 21816 & 0.0735 \\
\hline 2000 & 22150 & 22236 & 0.3889 \\
\hline 2100 & 22450 & 22630 & 0.8038 \\
\hline 2200 & 22700 & 23001 & 1.3270 \\
\hline 2300 & 22900 & 23351 & 1.9675 \\
\hline 2400 & 23100 & 23680 & 2.5118 \\
\hline 2500 & 23250 & 23992 & 3.1907 \\
\hline 2600 & 23400 & 24287 & 3.7899 \\
\hline
\end{tabular}


The sum of squares of $\%$ deviation (in the saturated zone for $\left.I_{f}>=800 A\right)=85.24$

\section{MODIFIED FROLICH'S EQUATION}

Frolich proposed a modified form which gives less error. It is given by equation

$E_{f}=\frac{a I_{f}}{b+I_{f}}+c I_{f}$

Fitting modified Frolich's equation to saturation curve is a little more difficult as it cannot be reduced to the linear regression form. The coefficients $a, b$ are found out by linear regression using eqn. 12, by varying values of $c$ in a loop (a recursive procedure) [14]:

$E_{f}^{\prime}=\frac{a I_{f}}{b+I_{f}}=E_{f}-c I_{f}$

The fitting eqn. (for modified Frolich) is given below:

$E_{f}=\frac{52853 I_{f}}{1735+I_{f}}-3.0 I_{f}$

Checking the fitting:

The actual values are being compared to the calculated values, using modified Frolich's method and are given in table 4 .

Table 4. Actual and calculated values by the modified Frolich's method

\begin{tabular}{|c|c|c|c|}
\hline $\begin{array}{c}\text { Field } \\
\text { Current, } \\
\text { A }\end{array}$ & Eactual & Ecalcu. & $\begin{array}{c}\% \\
\text { deviation }\end{array}$ \\
\hline 800 & 14200 & 14277 & 0.5429 \\
\hline 900 & 15600 & 15350 & -1.6038 \\
\hline 1000 & 16700 & 16322 & -2.2625 \\
\hline 1100 & 17700 & 17205 & -2.7980 \\
\hline 1200 & 18500 & 18007 & -2.6660 \\
\hline 1300 & 19100 & 18736 & -1.9047 \\
\hline 1400 & 19650 & 19400 & -1.2725 \\
\hline 1500 & 20100 & 20004 & -0.4770 \\
\hline 1600 & 20600 & 20554 & -0.2229 \\
\hline 1700 & 21000 & 21055 & 0.2598 \\
\hline 1800 & 21400 & 21510 & 0.5128 \\
\hline 1900 & 21800 & 21923 & 0.5660 \\
\hline 2000 & 22150 & 22299 & 0.6719 \\
\hline 2100 & 22450 & 22639 & 0.8420 \\
\hline 2200 & 22700 & 22947 & 1.0868 \\
\hline 2300 & 22900 & 23224 & 1.4160 \\
\hline 2400 & 23100 & 23474 & 1.6186 \\
\hline 2500 & 23250 & 23698 & 1.9250 \\
\hline 2600 & 23400 & 23897 & 2.1242 \\
\hline
\end{tabular}

The sum of squares of \% deviation (in the saturated zone for If $>=$ $800 \mathrm{~A})=44.28$

Another method is that of piece-wise linearization on the basis of straight line segments between data points. The computation is lengthier but the accuracy is more.

\section{CONCLUSIONS}

Secondary effects are neglected in simplified modeling using generalized machine theory. Saturation is one of the secondary effects which affect the performance variables and it should be accounted for. There has been many modeling approach to account for saturation. The first one is the use of saturated synchronous reactance in place of the unsaturated one. This is covered by Kingsley's method. A better method has been suggested by Anderson and Fouad. They have suggested an exponential form. The coefficients have been found out by using data for p.u. voltages of 1.0 and 1.2. A still better method is the exponential method, in which curvefitting has been obtained by linear regression. Due to the use of curve-fitting procedure, the error is relatively less. Another fitting equation was proposed by Frolich. This equation has also been fitted using linear regression. The error is less than that for fitting exponential equation. Later on, Frolich suggested a modified equation for better matching. That could also be fitted using a combination of recursive methods and linear regression. The error in this case is much smaller compared to other methods, but the procedure is a little more complex. Piecewise linearization is another popularly used method.

\section{REFERENCES}

[1] Venikov V. (1977). Transient processes in electric power system, Book, MIR Publishers.

[2] Adkins B., Harley R.G. (1975). Generalized theory of A.C. machines, Book, Chapman \& Hall, London.

[3] Anderson P.M., Fouad A.A. (2011). Power system control and stability, 2nd. Ed., IEEE Press, WileyInterscience.

[4] Kundur P. (2011). Power system stability and control, McGraw-Hill Inc., the EPRI Power System Engineering Series.

[5] Murty P.S.R. Modelling of power system components, Book, B.S. Publications, India.

[6] Kopylov I.P. (1984). Mathematical models of electric machines, MIR Publications, Moscow.

[7] Okabe M., Okada M., Tsuchiya H. (1983). Effects of magnetic characteristics of materials on the iron loss in the three-phase transformer core, IEEE Trans. Magn, Vol. 19, No. 5, pp. 2192-2194.

[8] Hayt W.H. Engineering circuit analysis, 6/e Tata Mcgraw-Hill.

[9] Shawney A.K. A course in electrical machine design, Dhanpat Rai and Co., New Delhi.

[10] Say M.G. Performance and design of AC machines, CBS Publishers and Distributors Pvt. Ltd.

[11] Kambo N.S. (1991). Mathematical programming techniques, revised edition, 1991, 1984, Affiliated East-West Press Pvt. Ltd. New Delhi-110 001, ISBN 81-85336-47-4.

[12] Ramamoorty M. (1987). Computer-aided design of electrical equipment, Affiliated East-West Press, ISBN: 81-85095-57-4 New Delhi, ISBN 81 8509557-4.

[13] Kreyszig E. (2001). Advanced engineering mathematics, Wiley, New York.

[14] Rajaraman V. Computer-oriented numerical methods, Prentice Hall of India.

[15] Bimbhra P.S. Electrical Machinery, Khanna Publishers, ISBN: 81-7409-016-9 
[16] Bharat Heavy Electricals Ltd., Operating Manual on $210 \mathrm{MW}$ turbogenerator-set.

\section{NOMENCLATURE}

$r_{a}, x_{a}:$ Armature resistance/ leakage reactance

$\mathrm{K}$ : $\quad$ Saturation factor
$X_{d u}$ : Unsaturated synchronous reactance

$X_{d s}: \quad$ Saturated synchronous reactance

$V_{t}, V_{t h}:$ Terminal, threshold voltage

$V_{\Delta}: \quad$ Difference voltage from threshold.

$S_{G}: \quad$ P.U. saturation factor 